\title{
Peripheral neuropathy in patients with CPEO associated with single and multiple mtDNA deletions
}

\section{OPEN}

Diana Lehmann, MD

Malte E. Kornhuber, MD Carolina Clajus, MD Charlotte L. Alston, PhD Andreas Wienke, PhD Marcus Deschauer, MD Robert W. Taylor, PhD Stephan Zierz, MD

Correspondence to Dr. Lehmann: diana.lehmann@uk-halle.de

Supplemental data at Neurology.org/ng

\section{ABSTRACT}

Objective: To characterize peripheral nerve involvement in patients with chronic progressive external ophthalmoplegia (CPEO) with single and multiple mitochondrial DNA (mtDNA) deletions, based on clinical scores and detailed nerve conduction studies.

Methods: Peripheral nerve involvement was prospectively investigated in 33 participants with CPEO (single deletions $n=18$ and multiple deletions $n=15$ ). Clinically, a modified Total Neuropathy Score (mTNS) and a modified International Cooperative Ataxia Rating Scale (mICARS) were used. Nerve conduction studies included Nn. suralis, superficialis radialis, tibialis, and peroneus mot. Early somatosensory evoked potentials were obtained by N. tibialis stimulation.

Results: Participants with multiple deletions had higher mTNS and mICARS scores than those with single deletions. Electrophysiologically in both sensory nerves ( $\mathrm{N}$. suralis and $\mathrm{N}$. radialis superficialis), compound action potential (CAP) amplitudes and nerve conduction velocities were lower and mostly abnormal in multiple deletions than those in single deletions. Early somatosensory evoked potentials of N. tibialis revealed increased P40 latencies and decreased N35-P40 amplitudes in multiple deletions. Both sensory nerves had higher areas under the receiver operating characteristic curves for the decreased CAP amplitudes than the 2 motor nerves. The $\mathrm{N}$. suralis had the best Youden index, indicating a sensitivity of $93.3 \%$ and a specificity of $72.2 \%$ to detect multiple deletions.

Conclusions: Peripheral nerve involvement in participants with multiple mtDNA deletions is an axonal type of predominant sensory neuropathy. This is clinically consistent with higher mTNS and mICARS scores. Sensory nerve involvement in participants with multiple deletions was not correlated with age at onset and duration of disease. Neurol Genet 2016;2:e113; doi: 10.1212/ NXG.0000000000000113

\section{GLOSSARY}

AUC $=$ area under the curve; CAP = compound action potential; CPEO = chronic progressive external ophthalmoplegia; mICARS = modified International Cooperative Ataxia Rating Scale; $\mathbf{m t D N A}=$ mitochondrial DNA; $\mathbf{m T N S}=$ modified Total Neuropathy Score; $\mathbf{N C V}=$ nerve conduction velocity; SANDO = sensory ataxic neuropathy with dysarthria and ophthalmoparesis.

Chronic progressive external ophthalmoplegia (CPEO) is the main clinical symptom associated with single, large scale, and multiple deletions of mitochondrial DNA (mtDNA). Peripheral neuropathy is a typical but variably expressed additional symptom. ${ }^{1-3}$ However, reports about peripheral neuropathy in patients with single deletions are rare. ${ }^{4-6}$ Electrophysiologic studies in mitochondrial diseases usually revealed a predominantly axonal type of nerve fiber damage. ${ }^{7-15}$ However, a predominantly demyelinating pattern or a mixed axonal and demyelinating type of peripheral nerve involvement has also been found. ${ }^{4,11,16}$ Sural nerve biopsies revealed axonal degeneration ${ }^{12,13}$ or demyelination. ${ }^{11}$ It has already been shown that patients with multiple

Form the Department of Neurology (D.L., M.E.K., C.C., S.Z.), Institute of Medical Epidemiology, Biometrics and Informatics (A.W.), University of Halle-Wittenberg, Halle/Saale, Germany; Wellcome Trust Centre for Mitochondrial Research (C.L.A., R.W.T.), Institute of Neuroscience, The Medical School, Newcastle University, UK; and Department of Neurology (M.D.), Technical University Munich, Germany.

Funding information and disclosures are provided at the end of the article. Go to Neurology.org/ng for full disclosure forms. The Article Processing Charge was paid by the Newcastle University.

This is an open access article distributed under the terms of the Creative Commons Attribution License 4.0 (CC BY), which permits unrestricted use, distribution, and reproduction in any medium, provided the original work is properly cited. 
deletions (clinically SANDO [sensory ataxic neuropathy with dysarthria and ophthalmoparesis] syndrome) had reduced compound action potential (CAP) amplitudes in predominantly sensory nerves. Clinically, they might often present as SANO or SANDO syndrome. ${ }^{17}$ There is only one previous study systematically comparing peripheral nerve involvement in patients with CPEO with single and multiple mtDNA deletions. ${ }^{18}$ In that study, it has been postulated that peripheral neuropathy is a rare finding in patients with CPEO with single deletions compared with that in patients with $\mathrm{CPEO}$ with $\mathrm{mtDNA}$ point mutations, multiple mtDNA deletions, and nuclear defects. However, in that study, only one patient with single mtDNA deletion and peripheral nerve involvement has been investigated. Four other patients had the typical mitochondrial encephalomyopathy, lactic acidosis, and stroke-like episode mtDNA point mutation. Nine other patients had the nuclear POLG mutation, but multiple deletions have not been analyzed in 3/9 patients. In 2 patients with multiple deletions, the nuclear defect has not been identified. In all these patients, no detailed clinical and neurophysiologic data were presented, and no quantitative electrophysiologic data were provided. ${ }^{18}$

In the present study, peripheral nerve involvement was prospectively investigated in 33 participants who had CPEO (single deletions $\mathrm{n}=18$ and multiple deletions of nuclear defects $\mathrm{n}=15$ ). Based on clinical scores and detailed nerve conduction studies, it could be shown that there was a more severe predominant sensory neuropathy in participants with multiple than with single deletions.

METHODS Participants. A total of 33 participants with CPEO associated with mtDNA deletions were included (single deletions $\mathrm{n}=18$ participants and multiple deletions $\mathrm{n}=15$ participants). The whole period of participants' recruitment was 4 years. Single deletions varied in length between 2 and $6.5 \mathrm{~kb}$ (median 5). The common $4.9 \mathrm{~kb}$ deletion was identified in 4 patients. The nuclear defects are shown in table 1 . The nuclear molecular defect of 1 participant could not be identified (ANT1, Twinkle, POLG1, and POLG2 were investigated). Genetic findings of 3 participants with multiple deletions were published previously. ${ }^{19,20}$ Clinical data of participants with multiple and single deletions are shown in table 2 .

Standard protocol approvals and participant consent. Genetics, electrophysiologic studies, and data analysis were performed in compliance with protocols approved by the Ethical
Table 1 Summary of genetic data of 15 participants with multiple deletions

M ANT1: p.A90D (heterozygote)

M ANT1: p.A90D (heterozygote)

M POLG: p.G848S/p.A899T (heterozygote)

F POLG: p.G848S/p.A899T ${ }^{\text {b }}$ (heterozygote)

M POLG: p.A467T/p.A467T (homozygote)

M POLG: p.A467T/p.W748S ${ }^{\mathrm{b}}$ (heterozygote)

F POLG: p.Ala467Thr/p.Met919Leu (heterozygote)

F POLG: p.T2511/p.P587L/p.R627Qb (heterozygote)

F POLG: p.Thr251lle/p.Pro587Leu (heterozygote)

F Twinkle (PEO1): p.K319Ta (heterozygote)

F Twinkle (PEO1): p.Arg354Pro (heterozygote)

M Twinkle (PEO1): p.Lys319Glua (heterozygote)

M Twinkle (PEO1): p.Lys319Glua (heterozygote)

F Twinkle (PEO1): p.Met114Arg/p.Met455Val ${ }^{\text {b }}$ (heterozygote)

F $\quad$ Not detected

${ }^{a}$ Dominant mutation.

${ }^{\mathrm{b}}$ Recessive mutation.

Committee of the Martin Luther University Halle-Wittenberg. Written informed consent was obtained from all participants.

Procedure. Multiple and single deletions have been detected by Southern blot analysis and long-range PCR analysis. Genetic studies have been performed according to standard protocols. All 33 participants were clinically characterized using a modified Total Neuropathy Score ${ }^{21}$ (mTNS) (table 3) and a modified International Cooperative Ataxia Rating Scale ${ }^{22}$ (mICARS) (supplemental data at Neurology.org/ng). The modification of mTNS included the following points: the sensibility was examined and rated according to the clinical-neurologic examination; the autonomic symptoms were elicited. mICARS calculation: maximum were 94 points instead of 100 points because examination of eye movement in patients with $\mathrm{CPEO}$ had to be omitted. Electrophysiologic studies included nerve conduction studies of sensory nerves (N. suralis and N. sup. radialis), motor nerves (N. tibialis and $\mathrm{N}$. peroneus.), and evoked potentials of the N. tibialis (P40 latency and N35-P40 amplitude values). Nerves without measurable amplitude and therefore without measurable nerve conduction velocity (NCV) in electrophysiologic studies have been omitted from statistical analysis. However, these nerves have been separately indicated in the analysis of the age dependence of the neurographic results. Normal limits for electrophysiologic studies were assessed according to $\mathrm{Oh}^{23}$

RESULTS Clinical scores: mTNS and mICARS. Participants with single and multiple deletions both had abnormal mTNS and mICARS scores. However, both scores were higher in participants with multiple than those with single deletions (table 2). Two of 15 patients with multiple deletions presented with SANDO phenotype. In these 2 participants, neurography indicated a non-length-dependent neuropathy. 


\begin{tabular}{|c|c|c|c|}
\hline \multirow[t]{2}{*}{ Table 2} & \multicolumn{3}{|c|}{$\begin{array}{l}\text { data of participants with single and multiple mtDNA } \\
s, \pm S D\end{array}$} \\
\hline & $\begin{array}{l}\text { Single mtDNA } \\
\text { deletion } \\
\text { sample }(n=18)\end{array}$ & $\begin{array}{l}\text { Multiple mtDNA } \\
\text { deletion } \\
\text { sample }(n=15)\end{array}$ & $\begin{array}{l}\text { Statistical } \\
\text { significance }\end{array}$ \\
\hline Sex (F/M) & $18(12 / 6)$ & $15(8 / 7)$ & NS \\
\hline Age, y & $49 \pm 13$ & $57 \pm 12$ & NS \\
\hline Age at onset, $y$ & $27 \pm 14$ & $42 \pm 15$ & $p<0.01$ \\
\hline Duration of disease, $y$ & $22 \pm 4$ & $15 \pm 3$ & NS \\
\hline Heart block & $2 / 10$ & $3 / 15$ & NS \\
\hline Retinopathy & $5 / 17$ & $0 / 13$ & $p=0.052$ \\
\hline Diabetes mellitus & $3 / 18$ & $3 / 15$ & NS \\
\hline SANDO & $0 / 18$ & $2 / 15$ & NS \\
\hline mTNS & $4.6 / 32 \pm 3.5$ & $12.5 / 32 \pm 6.3$ & $p<0.001$ \\
\hline mICARS & $6.7 / 94 \pm 4.9$ & $15.5 / 94 \pm 10.9$ & $p<0.001$ \\
\hline
\end{tabular}

Abbreviations: mICARS $=$ modified International Cooperative Ataxia Rating Scale; mtDNA = mitochondrial DNA; mTNS = modified Total Neuropathy Score; NS = not significant; SANDO = sensory ataxic neuropathy with dysarthria and ophthalmoparesis.

Neurography. The differences of CAP and NCV in participants with single and multiple deletions were significant (figure 1, A and B). Sensory CAPs of the sural nerve were absent bilaterally in 7 and unilaterally in further $3 / 15$ participants with multiple mtDNA deletions in contrast to bilateral absence in 2/18 participants with single mtDNA deletions. Early somatosensory evoked potentials of N. tibialis stimulation showed in participants with multiple mtDNA deletions an increase of $\mathrm{P} 40$ latency $(p<0.005)$, while the N35-P40 amplitudes $(p<0.00005)$ were reduced, compared with participants with single mtDNA deletions. In participants with multiple deletions, there was no correlation between age at onset or duration of disease with NCVs (figure 1,
C-F) or CAP amplitudes (figure e-1). The 2 patients with SANDO were included in the overall cohort for the neuropathy/ataxia scores and all electrophysiologic studies. Reexamination of the data excluding the 2 patients with SANDO did not change the statistical results of the mICARS, mTNS, or electrophysiologic studies.

Statistical analysis of sensitivity and specificity of both sensory nerves (N. suralis and N. sup. radialis) showed the highest AUC (area under the [receiver operating characteristic] curve) levels. However, despite a higher AUC level, the N. suralis showed a better Youden index (figure 2). The decreased CAP amplitudes of the N. suralis had a sensitivity of $93.3 \%$ and a specificity of $72.2 \%$ (positive predictive value $=73.7 \%$ and negative predictive value $=$ 92.9\%) to detect multiple deletions.

DISCUSSION Peripheral neuropathy is a wellknown clinical feature in mitochondrial diseases. In a large phenotype/genotype analysis of 136 patients with CPEO with single mtDNA deletions, polyneuropathy has not been mentioned as a clinical finding. ${ }^{6}$ Another group found peripheral neuropathy in $8 \%$ of patients with CPEO with single mtDNA deletions. ${ }^{5}$ However, peripheral neuropathy has also been reported in $32 \%$ of patients with multiple mtDNA deletions due to mutations in the gene encoding polymerase gamma as well. ${ }^{24}$ Recently, 1 single deletion patient who had peripheral nerve involvement has been studied. ${ }^{18}$

In the present study, both groups of participants (single and multiple deletions) had higher mTNS and mICARS scores than normal. However, participants with multiple deletions had higher mTNS $(p<0.001)$ and mICARS $(p=0.009)$ values as

Table 3 Modified Total Neuropathy Score

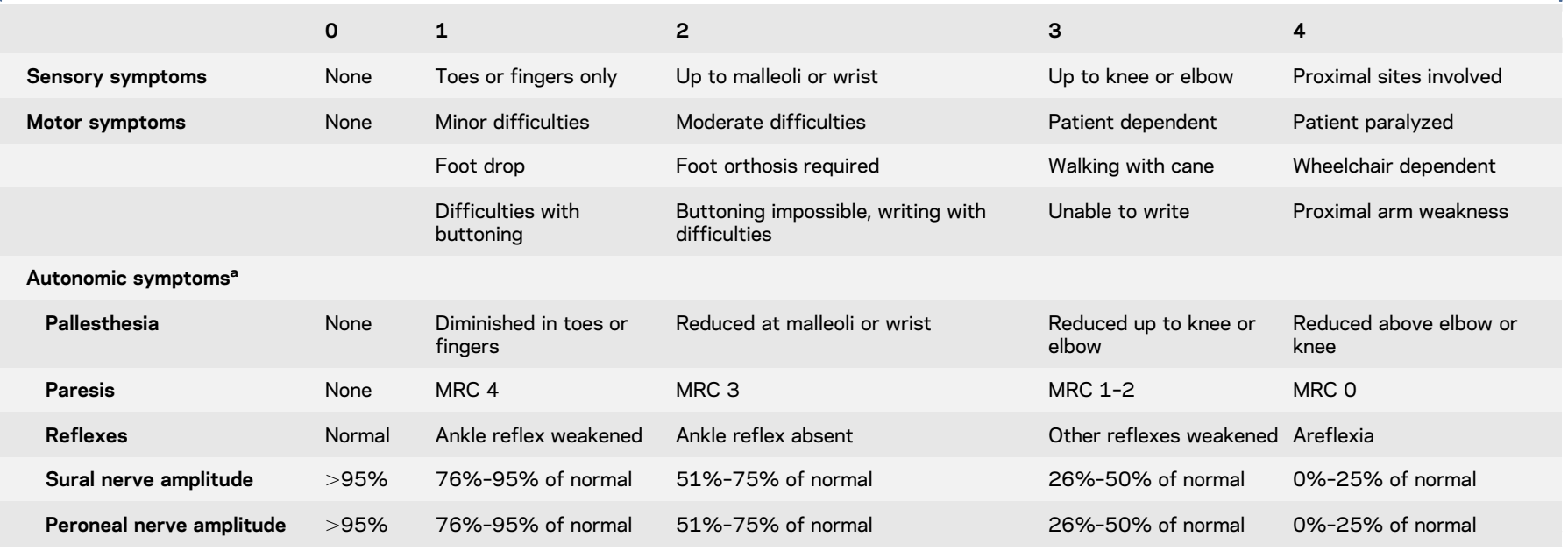

Abbreviation: MRC $=$ Medical Research Council.

a Urinary incontinence, imperative micturition, erectile dysfunction, fecal incontinence, vomiting, diarrhea, and orthostatic hypotension. 

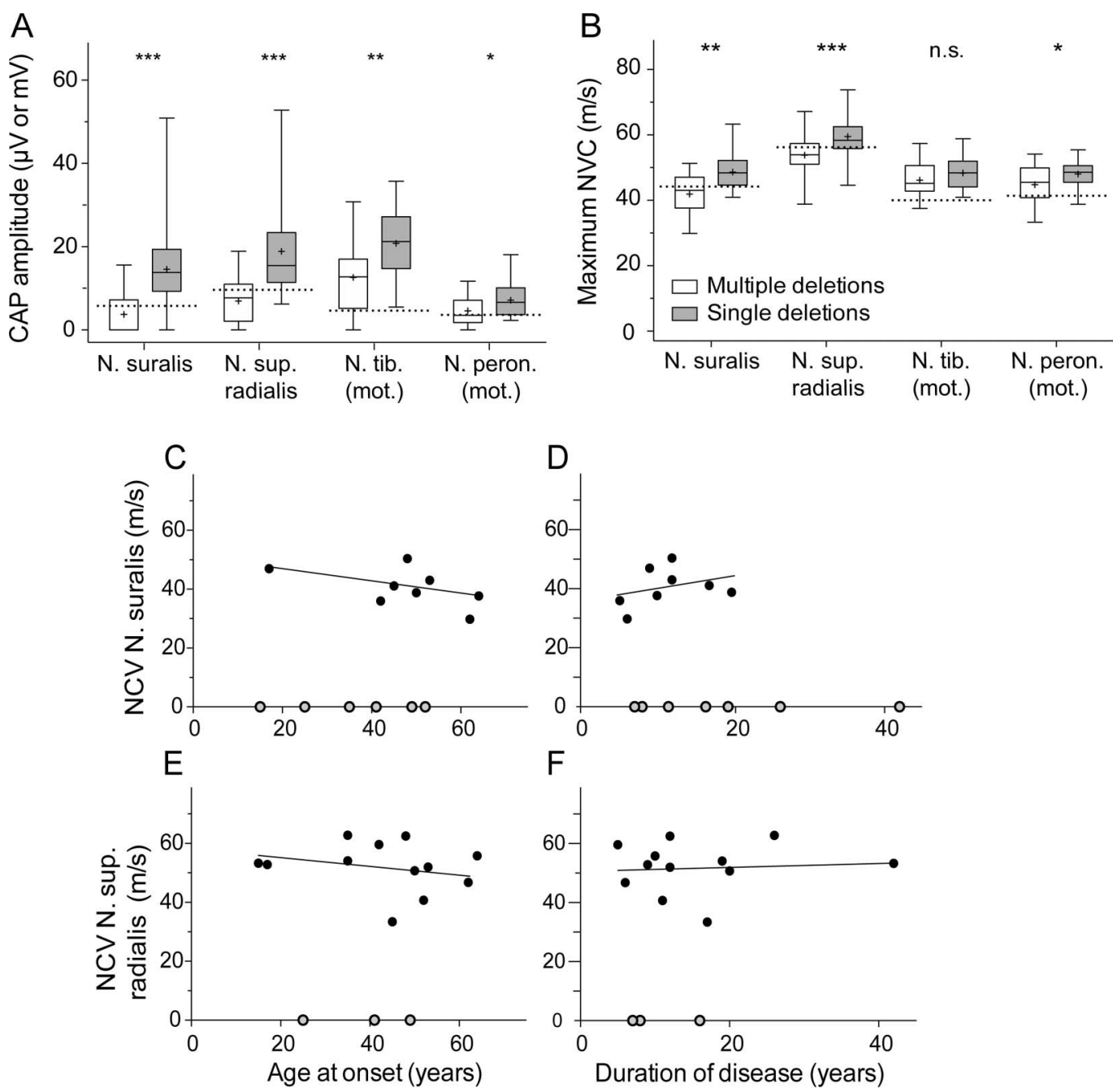

(A) Compound action potential (CAP) amplitudes of the N. suralis (single deletions $n=18$ and multiple deletions $n=15$ ), N. sup. radialis (single deletions $n=18$ and multiple deletions $n=15$ ), N. tibialis (mot.) (single deletions $n=18$ and multiple deletions $n=15$ ), and $N$. peroneus (mot.) (single deletions $n=18$ and multiple deletions $n=14$ ). $* p<0.005 ; * * p<0.0005$; $* * * p<0.000001$ (Mann-Whitney $U$ test). Bar shows the range of values. Dotted lines indicate limits of normal according to Oh. ${ }^{23}$ (B) Nerve conduction velocity (NCV) of N. suralis (single deletions $n=16$ and multiple deletions $n=8$ ), N. sup. radialis (single deletions $\mathrm{n}=18$ and multiple deletions $\mathrm{n}=12$ ), $\mathrm{N}$. tibialis (mot.) (single deletions $\mathrm{n}=18$ and multiple deletions $\mathrm{n}=$ 14 ), and $\mathrm{N}$. peroneus (mot.) (single deletions $\mathrm{n}=18$ and multiple deletions $\mathrm{n}=14$ ). $* p<0.05 ; * * p<0.005 ; * * * p<0.001$ (Mann-Whitney $U$ test). n.s. = not statistically significant. Bar shows the range of values. Dotted lines indicate limits of normal according to Oh. ${ }^{23}$ (C) Correlation of age at onset with NCV N. suralis $(n=8): p=0.3, r=-0.4$. (D) Correlation of duration of disease with NCV N. suralis $(n=8): p=0.3, r=0.5$. (E) Correlation of age at onset with NCV N. sup. radialis $(n=$ 12): $p=0.1, r=-0.5$. (F) Correlation of duration of disease and NCV N. sup. radialis $(n=12): p=0.3, r=0.3$. Gray dots indicate nerves without measurable amplitude and therefore without measurable NCV.

compared to those with single mtDNA deletions. However, the ICARS is validated for cerebellar disorders only, and high scores can therefore not be considered as proof of sensory ataxia. In fact, patients with CPEO may very well have high scores on the ICARS scale because of myogenic dysarthria or impaired gait due to cerebellar involvement or limb girdle weakness.

Participants with single mtDNA deletions appear to have an earlier age at onset (second decade of life) than patients with multiple mtDNA (age at onset: fourth decade of life). This is consistent with a further study. ${ }^{25}$ Recently, it has been shown that patients with single and multiple mtDNA deletions do not have differences in histopathologic analysis. ${ }^{26}$ Peripheral nerve involvement in multiple deletions did not correlate either with age at onset or duration of disease, indicating that peripheral nerve involvement is a symptom not influenced by age at onset or duration of disease. Thus, the difference in age at onset in multiple and single mtDNA deletions can so far only be stated. The biological explanation remains enigmatic.

Electrophysiologically in both sensory nerves (N. suralis and N. radialis superficialis), CAP 

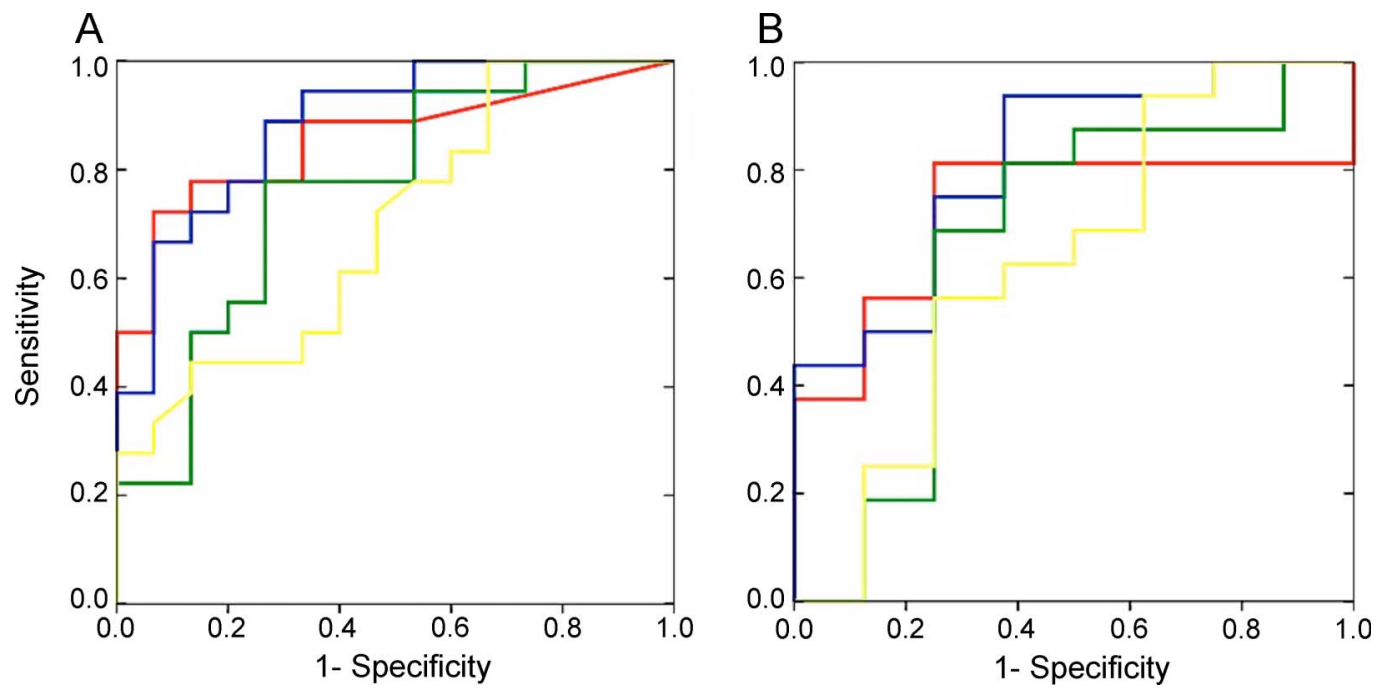

Compound action potential amplitudes (A) and nerve conduction velocities (B): statistical analysis of sensitivity and specificity to detect multiple deletions. N. suralis (red line), N. sup. radialis (blue line), N. tibialis (mot.) (green line), and N. peroneus (mot.) (yellow line).

amplitudes and NCV were lower and mostly abnormal in participants with multiple deletions. These findings are consistent with those of a previous study. ${ }^{17}$ The 2 motor nerves showed only slight differences. The 2 sensory nerves showed decreased CAP amplitudes and slightly decreased NCV values. This suggests that the nerve involvement is predominantly axonal. Fibers of the radial nerve were affected similarly to those of the sural nerve. Thus, length dependence is questionable in participants with multiple $\mathrm{mtDNA}$ deletions. The sensory involvement was supported by early somatosensory evoked potentials, showing that participants with multiple mtDNA deletions had an increase of P40 latency $(p<0.005)$, while the according N35-P40 amplitude values were reduced $(p<0.00005)$.

In a previous study, it has been shown that the number of dorsal root ganglion cells and also posterior horn cells was lower in a patient with pA467T/ pX1240Q mutations of the POLG gene as compared to that in control subjects. ${ }^{3}$ Anterior horn cells were also relatively low in number in this patient, but the difference to the controls did not reach significance. ${ }^{3}$ Therefore, it can be hypothesized that sensory neuropathy in patients with multiple mtDNA deletions is not only of the axonal type but also might additionally be caused by nerve cell loss.

Recently, it has been shown that peripheral neuropathy in patients with mitochondrial ophthalmoplegia had the highest specificity (91\%) for the diagnosis of a nuclear DNA defect. ${ }^{18}$ In the same study, it has been suggested that peripheral neuropathy is a rare finding in patients with single deletions. This is consistent with the present study. Electrophysiologically, both sensory nerves CAP amplitudes and NCV were lower and mostly abnormal in multiple deletions than those in single deletions. However, in the previous study, large fiber peripheral neuropathy was found in only 16/77 patients. Large deletions were seen in 9 of these 16 patients. Of the remaining 5 patients, 1 was a single deletions and 4 were point mutations. ${ }^{18}$ In the present, decreased CAP amplitudes of the sural nerve had a sensitivity of $93.3 \%$ and a specificity of $72.2 \%$ (positive predictive value $=73.7 \%$ and negative predictive value $=92.9 \%)$ to detect multiple deletions.

Clinical and electrophysiologic findings of predominant sensory nerve involvement support the notion that sensory neuropathy is not restricted to SANDO syndrome but rather indicates that peripheral sensory nerve involvement is frequent in patients with multiple deletions caused by nuclear defects.

\section{AUTHOR CONTRIBUTIONS}

D.L.: experimental work and preparation of manuscript. M.E.K.: electrophysiologic studies, concept, interpretation of the data, and critical review. C.C.: electrophysiologic studies. C.L.A.: experimental work. A.W.: statistical interpretation of the data. M.D.: interpretation of the data and critical review. R.W.T.: interpretation of the data and critical review. S.Z.: concept, supervision, interpretation of the data, and critical review.

\section{ACKNOWLEDGMENT}

The authors acknowledge the technical assistance of Thekla Wangemann and Kathleen Zietz.

\section{STUDY FUNDING}

D.L., M.D., and S.Z. are members of the German mitoNET funded by the German Ministry of Education and Research. C.L.A. is the recipient of a National Institute for Health Research (NIHR) doctoral fellowship (NIHRHCS-D12-03-04). R.W.T. is supported by the Wellcome Trust Centre for Mitochondrial Research (096919Z/11/Z), the Medical Research Council (UK) Centre for Translational Muscle Disease Research 
(G0601943), The Lily Foundation, and the UK NHS Highly Specialised Commissioners which funds the "Rare Mitochondrial Disorders of Adults and Children" Diagnostic Service in Newcastle upon Tyne (newcastle-mitochondria.com). The views expressed are those of the authors and not necessarily those of the NHS, the NIHR, or the Department of Health.

\section{DISCLOSURE}

Dr. Lehmann, Dr. Kornhuber, Dr. Clajus, and Ms. Alston report no disclosures. Mr. Wienke has served on the editorial board of Biostatistics. Dr. Deschauer has received travel funding/speaker honoraria from Sanofi Genzyme and Ultragenyx and has received research support from Deutsche Gesellschaft für Muskelkranke (German Society for People with Muscular Disorders). Dr. Taylor reports no disclosures. Dr. Zierz has received speaker honoraria from Genzyme. Go to Neurology.org/ng for full disclosure forms.

Received April 14, 2016. Accepted in final form September 7, 2016.

\section{REFERENCES}

1. Kaufmann P, Pascual JM, Anziska Y, et al. Nerve conduction abnormalities in patients with MELAS and the A3243G mutation. Arch Neurol 2006;63:746-748.

2. Garone C, Tadesse S, Hirano M. Clinical and genetic spectrum of mitochondrial neurogastrointestinal encephalomyopathy. Brain 2011;134:3326-3332.

3. Lax NZ, Whittaker RG, Hepplewhite PD, et al. Sensory neuronopathy in patients harbouring recessive polymerase gamma mutations. Brain 2012;135:62-71.

4. Molnar M, Zanssen S, Buse G, Schroder JM. A large-scale deletion of mitochondrial DNA in a case with pure mitochondrial myopathy and neuropathy. Acta Neuropathol 1996;91:654-658.

5. Laforet P, Lombes A, Eymard B, et al. Chronic progressive external ophthalmoplegia with ragged-red fibers: clinical, morphological and genetic investigations in 43 patients. Neuromuscul Disord 1995;5:399-413.

6. Yamashita S, Nishino I, Nonaka I, Goto Y. Genotype and phenotype analyses in 136 patients with single large-scale mitochondrial DNA deletions. J Hum Genet 2008;53: 598-606.

7. Chu CC, Huang CC, Fang W, Chu NS, Pang CY, Wei YH. Peripheral neuropathy in mitochondrial encephalomyopathies. Eur Neurol 1997;37:110-115.

8. Eymard B, Penicaud A, Leger JM, et al. Clinical and electrophysiologic study of the peripheral nerve in 28 cases of mitochondrial disease [in French]. Revue Neurol (Paris) 1991;147:508-512.

9. Schubert M, Zierz S, Dengler R. Central and peripheral nervous system conduction in mitochondrial myopathy with chronic progressive external ophthalmoplegia. Electroencephalogr Clin Neurophysiol 1994;90:304-312.

10. Girlanda P, Toscano A, Nicolosi C, et al. Electrophysiological study of neuromuscular system involvement in mitochondrial cytopathy. Clin Neurophysiol 1999;110: 1284-1289.
11. Mizusawa H, Ohkoshi N, Watanabe M, Kanazawa I. Peripheral neuropathy of mitochondrial myopathies. Revue Neurol (Paris) 1991;147:501-507.

12. Yiannikas C, McLeod JG, Pollard JD, Baverstock J. Peripheral neuropathy associated with mitochondrial myopathy. Ann Neurol 1986;20:249-257.

13. Peyronnard JM, Charron L, Bellavance A, Marchand L. Neuropathy and mitochondrial myopathy. Ann Neurol 1980;7:262-268.

14. Fadic R, Russell JA, Vedanarayanan VV, Lehar M, Kuncl RW, Johns DR. Sensory ataxic neuropathy as the presenting feature of a novel mitochondrial disease. Neurology 1997;49:239-245.

15. Santoro L, Manganelli F, Lanzillo R, et al. A new POLG1 mutation with PEO and severe axonal and demyelinating sensory-motor neuropathy. J Neurol 2006;253:869-874.

16. Bardosi A, Friede RL, Ropte S, Goebel HH. A morphometric study on sural nerves in metachromatic leucodystrophy. Brain 1987;110:683-694.

17. Hanisch F, Kornhuber M, Alston CL, Taylor RW, Deschauer M, Zierz S. SANDO syndrome in a cohort of 107 patients with CPEO and mitochondrial DNA deletions. J Neurol Neurosurg Psychiatry 2015;86:630-634.

18. Horga A, Pitceathly RD, Blake JC, et al. Peripheral neuropathy predicts nuclear gene defect in patients with mitochondrial ophthalmoplegia. Brain 2014;137:3200-3212.

19. Deschauer M, Hudson G, Muller T, Taylor RW, Chinnery PF, Zierz S. A novel ANT1 gene mutation with probable germline mosaicism in autosomal dominant progressive external ophthalmoplegia. Neuromuscul Disord 2005;15:311-315.

20. Hudson G, Deschauer M, Busse K, Zierz S, Chinnery PF. Sensory ataxic neuropathy due to a novel C10Orf2 mutation with probable germline mosaicism. Neurology 2005; 64:371-373.

21. Cornblath DR, Chaudhry V, Carter K, et al. Total neuropathy score: validation and reliability study. Neurology 1999;53:1660-1664.

22. Trouillas P, Takayanagi T, Hallett M, et al. International Cooperative Ataxia Rating Scale for pharmacological assessment of the cerebellar syndrome. The Ataxia Neuropharmacology Committee of the World Federation of Neurology. J Neurol Sci 1997;145:205-211.

23. Oh SJ. Clinical Electromyography: Nerve Conduction Studies, 3rd ed. Philadelphia: Lippincott Williams \& Wilkins; 2003.

24. Horvath R, Hudson G, Ferrari G, et al. Phenotypic spectrum associated with mutations of the mitochondrial polymerase gamma gene. Brain 2006;129:1674-1684.

25. Kawai H, Akaike M, Yokoi K, et al. Mitochondrial encephalomyopathy with autosomal dominant inheritance: a clinical and genetic entity of mitochondrial diseases. Muscle Nerve 1995;18:753-760.

26. Zierz CM, Joshi PR, Zierz S. Frequencies of myohistological mitochondrial changes in patients with mitochondrial DNA deletions and the common m.3243A $>\mathrm{G}$ point mutation. Neuropathology 2015;35:130-136. 


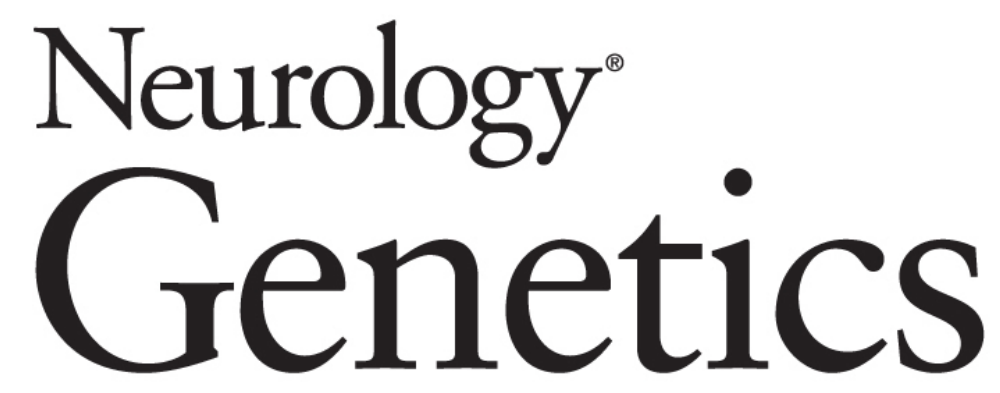

Peripheral neuropathy in patients with CPEO associated with single and multiple mtDNA deletions

Diana Lehmann, Malte E. Kornhuber, Carolina Clajus, et al. Neurol Genet 2016;2;

DOI 10.1212/NXG.0000000000000113

This information is current as of October 19, 2016

Neurol Genet is an official journal of the American Academy of Neurology. Published since April 2015, it is an open-access, online-only, continuous publication journal. Copyright ( 2016 American Academy of Neurology. All rights reserved. Online ISSN: 2376-7839.

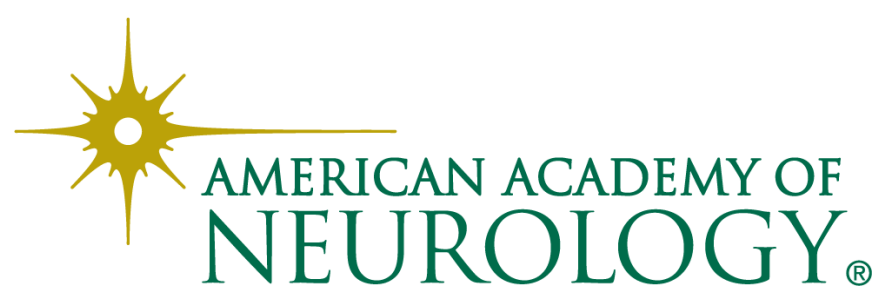




\section{Updated Information \&} Services

\section{Supplementary Material}

References

Subspecialty Collections

Permissions \& Licensing

Reprints including high resolution figures, can be found at: http://ng.neurology.org/content/2/6/e113.full.html

Supplementary material can be found at: http://ng.neurology.org/content/suppl/2016/10/19/2.6.e113.DC1

This article cites 25 articles, 1 of which you can access for free at: http://ng.neurology.org/content/2/6/e113.full.html\#\#ref-list-1

This article, along with others on similar topics, appears in the following collection(s):

All clinical neurophysiology

http://ng.neurology.org//cgi/collection/all_clinical_neurophysiology Evoked Potentials/Somatosensory

http://ng.neurology.org//cgi/collection/evoked_potentials-somatosensor y

Mitochondrial disorders

http://ng.neurology.org//cgi/collection/mitochondrial_disorders

Ocular motility

http://ng.neurology.org//cgi/collection/ocular_motility

Peripheral neuropathy

http://ng.neurology.org//cgi/collection/peripheral_neuropathy

Information about reproducing this article in parts (figures,tables) or in its entirety can be found online at:

http://ng.neurology.org/misc/about.xhtml\#permissions

Information about ordering reprints can be found online: http://ng.neurology.org/misc/addir.xhtml\#reprintsus

Neurol Genet is an official journal of the American Academy of Neurology. Published since April 2015, it is an open-access, online-only, continuous publication journal. Copyright ( 2016 American Academy of Neurology. All rights reserved. Online ISSN: 2376-7839.

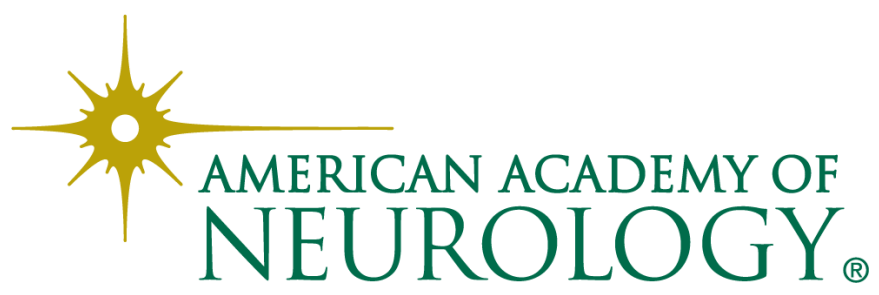

